\title{
Towards equity in school funding policies
}

A strong economic recovery that improves prospects for equitable growth after the COVID-19 pandemic will need to address persistent inequity in school systems. About two-thirds of OECD governments have increased education budgets in response to the pandemic. While the overall level of available resources matters, their allocation is at least as important. At the same time, governments will also need to make difficult budgetary choices to support the recovery, and balance short-term and long-term economic and social goal. The pursuit of equity in school systems can go hand in hand with efficiency goals when it comes to the allocation of available resources. Funding approaches play an important role in achieving equity objectives. Ensuring that students with different needs and from different backgrounds have access to high quality education from an early age, for example, can be an effective means to reduce systemic inefficiencies (Johnson and Jackson, 2019 ${ }_{[1]}$ ). Drawing on evidence from the OECD School Resources Review and beyond, this policy brief explores how school funding policies can promote equitable learning opportunities for all students. In particular, this brief explores the following questions:

- How can school systems ensure adequate levels of resources across sub-central authorities?

- How can school funding approaches provide additional resources to schools most in need?

- What is the role of transparency and evaluation for equity in school funding?

About two-thirds of OECD governments raised their budget for education in response to the COVID-19 pandemic, with the remainder maintaining a constant budget (OECD, 2021 $\left[{ }_{[2]}\right]$. In addition, budgets devoted to education continued to increase in 2021. The economic recovery is, however, uneven and sizeable uncertainty remains. As governments across the OECD face different policy challenges in terms of employment and output (OECD, 2021 ${ }_{[3]}$ ), they will need to make difficult budgetary choices to support the recovery, and balance short-term and long-term economic and social goals.

A strong economic recovery that improves prospects for equitable growth (OECD, 2021 [3]) will need to address persistent inequity in school systems. Students from socio-economically disadvantaged backgrounds or from rural areas have, for instance, experienced substantial challenges during the pandemic. Evidence from the OECD Programme for International Student Assessment (PISA) 2018 showed that students from socio-economically disadvantaged schools were less likely to have access to a computer for schoolwork and, in some countries, to benefit from an Internet connection at home. In addition, perceptions of greater shortages or inadequate digital technologies were also more recurrent among principals from disadvantaged schools. At the system level, education systems where material resources are allocated inequitably among socio-economically advantaged and disadvantaged schools, tend to display lower student performance (Figure 1). 


\section{Figure 1. Allocation of material resources related to schools' socio-economic profile and reading performance}

Results based on principals' reports

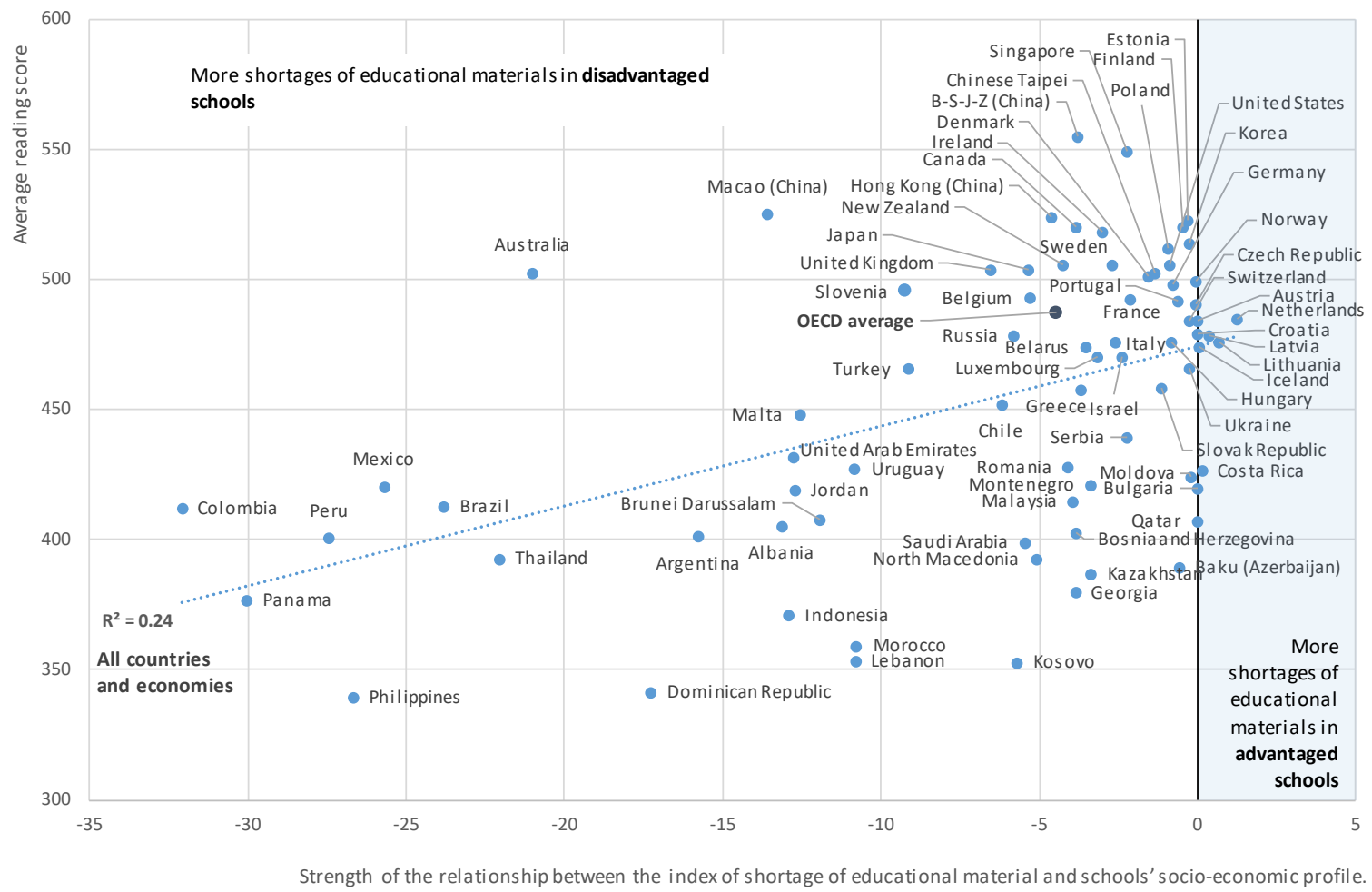

Note: This is the strength of the association between the school's socio-economic profile and the principal's concern about the educational material at the school. Positive values indicate that principals of socio-economically advantaged schools are more concerned than principals of disadvantaged schools. Negative values indicate that principals of disadvantaged schools are more concerned than principals of advantaged schools. A value of 0 means there is no difference between advantaged and disadvantaged schools.

Source: (OECD, 2020[4]]), PISA 2018 Results (Volume V): Effective Policies, Successful Schools, Table I.B1.4 and Table V.B1.5.5, https://doi.org/10.1787/ca768d40-en.

The overall level of investment in education is an important precondition for a quality provision for all students (Jackson, 2018[5]). Schools that lack quality teachers and leaders, adequate infrastructure and educational materials will have more difficulties to provide a high quality learning experience. Even school systems with comparatively high levels of funding may face resource challenges, which often affect disadvantaged areas or schools, thus raising serious equity concerns. In the United States, for example, finance reforms directed to guarantee an adequate provision of resources in low income schools were crucial to reduce overall achievement gaps between high and low income school districts (Lafortune, Rothstein and Schanzenbach, 2018[6]; Jackson, Johnson and Persico, 2016[7]]).

While overall levels of investment matter, beyond a certain level of investment what matters most is how funding is allocated to schools that are most in need of additional resources. In response to the pandemic, OECD countries used a range of criteria to allocate additional expenditure in education. While $50 \%$ of them relied on the number of students/classes, around $40 \%$ used the proportion of students with special socio-economic characteristics and $30 \%$ the proportion of those with special needs (OECD, $2021_{[8]}$ ). 
Ensuring an equitable distribution of resources across schools requires attention to both horizontal equity (i.e. allocating similar levels of resources to similar types of provision) and vertical equity (i.e. allocating different levels of resources to student groups with different needs). While both concepts of equity seem to imply a trade-off, it is possible to allocate additional funding for schools with a higher proportion of students from disadvantaged backgrounds (vertical equity), while guaranteeing that such additional funding is identical for those groups of students or schools with similar characteristics (horizontal equity).

\section{Ensuring that all sub-central authorities have resources to meet the needs of their students}

Sub-central ${ }^{1}$ authorities are increasingly involved in raising resources for school education and making decisions on the allocation and management of funds. Reliance on own tax revenues may support sub-central authorities in determining public service levels in line with local preferences and help mobilise additional resources for school education. At the same time, it entails risks to create inequities in funding available for schools across different regions/states/localities. Typically, wealthier jurisdictions will be in a better position to raise their own revenues and to provide adequate funding per student than less wealthy ones.

In such contexts, fiscal transfer systems have an important role to play in equalising revenue levels and ensuring that all jurisdictions have the necessary resources to provide opportunities for their students. The extent of transfers of public funds from central to sub-central levels of government varies widely between countries (Figure 2). While fiscal transfers and grants go beyond the school sector, getting the system right is particularly important for school education, which often accounts for the largest share of the local budgets. The OECD School Resources Review provides examples from different countries that have introduced fiscal transfer and equalisation mechanisms alongside reforms that shifted responsibilities for school funding to the local level:

- When Brazil devolved authority from a highly centralised system to states and municipalities in the mid-1990s, it created a Fund for the Maintenance and Development of Basic Schools and the Valorisation of the Teaching Profession (Fundo para Manutenção e Desenvolvimento do Ensino Fundamental e Valorização do Magistério, FUNDEF) to reduce the large national inequalities in per-student spending. State and municipal governments were required to transfer a proportion of their tax revenue to FUNDEF, which redistributed it to state and municipal governments that could not meet specified minimum levels of per-student expenditure. FUNDEF (which was subsequently revised in 2007 in the form of the Maintenance and Development Fund for Basic Education- Fundo de Manutenção e Desenvolvimento da Educação Básica, FUNDEB) did not prevent wealthier regions from increasing their overall spending more rapidly than poorer regions, but played a highly redistributive role and increased both the absolute level of spending and the predictability of transfers. There is evidence that FUNDEF and then FUNDEB have been instrumental in reducing disparities in educational funding across municipalities (OECD, 2021[9]). FUNDEB is being relaunched with a new mandate and as a permanent feature of the school funding system in Brazil (OECD, 2021[9]).

\footnotetext{
${ }^{1}$ The central level specifies authorities that make decisions or participate in different aspects of decision making on a national scale. This includes, among others, the central government, central education, financial and legislative authorities and central auditing services. All authorities below the central level in administrative terms are referred to as sub-central level.
} 
Figure 2. Distribution of initial sources of public funds for education and change in government levels' share of funds after intergovernmental transfers (2018)

Primary, secondary and post-secondary non-tertiary education, in per cent

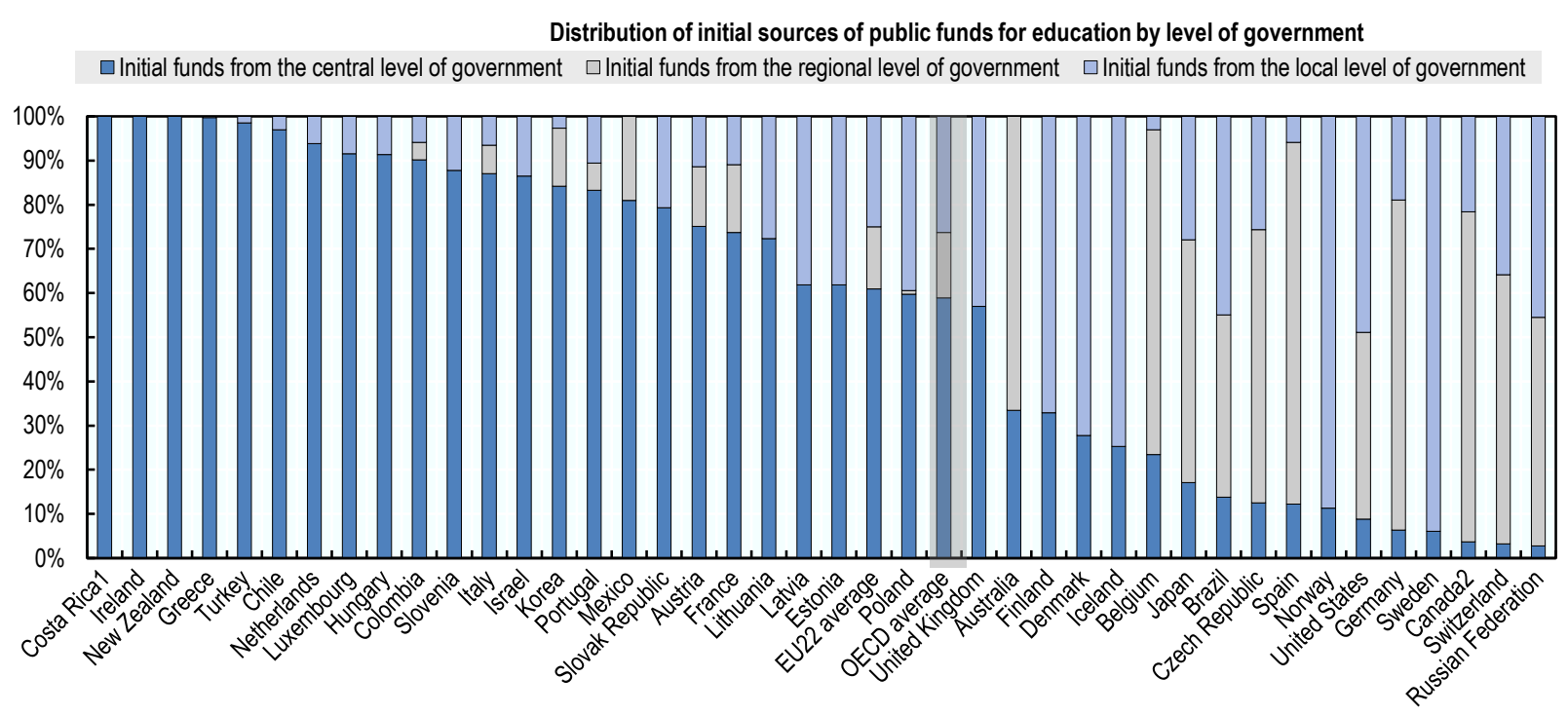

Change in government levels' share of funds after intergovernmental transfers

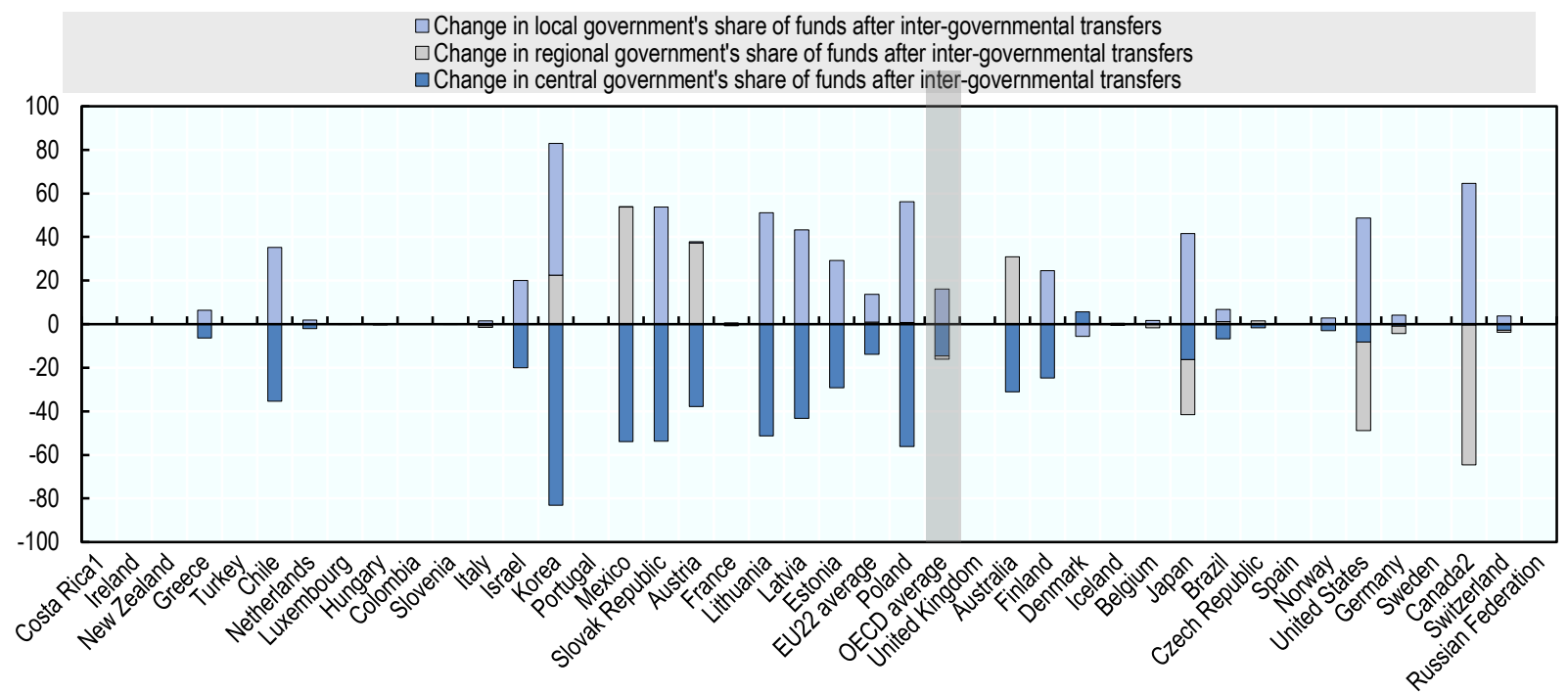

Note: 1. Year of reference 2019. 2. Primary, secondary and post-secondary non-tertiary education includes pre-primary programmes. Countries are ranked in descending order of the share of initial sources of funds from the central level of government.

Source: (OECD, 2021 [10]), Education at a Glance 2021: OECD Indicators, Table C4.2 (accessed on 14 October 2021), http://stats.oecd.org, Education at a Glance Database.

- By Constitution, Colombia's education system is decentralised. However, the financing of the public school system comes mainly from the national level. Regional and local authorities that have been certified to provide education (Entidades Territoriales Certificadas, ETC) receive a large share of their resources from the central government through the General System of Transfers (Sistema General de Participaciones, SGP) to provide the service of pre-primary, primary and secondary education. These transfers are complemented by the territorial entities' own resources, according to their responsibilities within the decentralisation model. The 
revenue sharing system, which pursues multiple public finance objectives, including education, also represents a tool for territorial and social compensation. Education resources are distributed among departments, districts and certified municipalities. A specific share per student is assigned annually based on conditions of equity and efficiency for every education level, differentiating geographic zone (urban-rural) and taking into account the number of students enrolled the previous year. These transfers do not take into account the fiscal capacity of the sub-national governments. In addition to the transfers from the SGP to the ETC for service provision, there are some additional resources that are transferred. An additional share of the resources distributed by student is allocated differentially with regard to the number of students with special needs (disabilities and special abilities), boarding schools where these are needed and for student connectivity. An additional fund is also distributed among schools and all districts and municipalities, both certified and not certified, specifically for quality improvement.

- In Denmark, municipalities are the main providers of public services, including primary and lower secondary education. Municipal spending is primarily financed through central government grants and local taxes. The total level of the grants is decided through annual negotiations between the central and local governments. The grant-level for a given municipality is based on the population size in the given municipality. In addition, there is a fiscal equalisation scheme, which on one hand takes into account tax revenue and on the other hand, expenditure needs depending on age composition and socio-economic structure in the municipalities. The fiscal equalisation scheme seeks to give municipalities a fairly similar financial basis depending on their population, so that all municipalities are able to provide a fairly similar service level across remits.

- In Poland, education decentralisation was part of the overall decentralisation process of the country initiated in 1990. The main transfer from the central to local budgets is called "general subvention" and is composed of a few separately calculated components. Two main ones are the education component and the equalisation component. The education component is calculated on the basis of student numbers (with numerous coefficients reflecting different costs of providing education to different groups of students), and thus reflects different costs of service provision. The equalisation component is based on a formula and equalises poorer jurisdictions up to $90 \%$ of average per capita revenues of similar local governments.

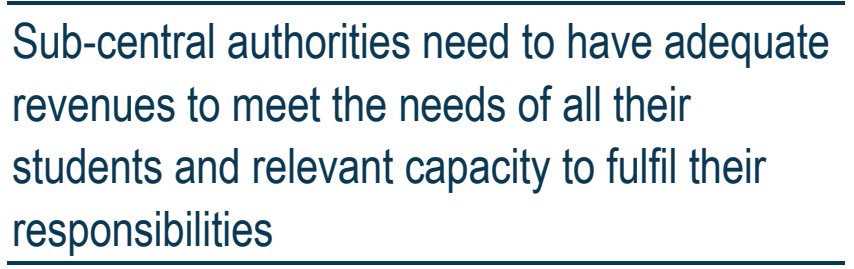

While funding availability for and resource allocation across sub-central authorities matter, building their resource management capacity should be a further priority to ensure all sub-central authorities can support the provision of high quality education. Competency frameworks for local leaders and administrators should reflect the related skills and be used to guide recruitment processes as well as training and professional development. In addition, professional development could be made available to staff and focus on, for instance, managing local school networks, financial planning, human resources management, quality assurance in education, etc. Networks of advisors could equally be established to support the education work of responsible authorities, and authorities could collaborate and share administrative and managerial resources and expertise. 


\section{Providing additional resources for disadvantaged schools}

\section{Main funding allocation vs. targeted funds}

A key concern in designing funding allocation mechanisms is to ensure that resources are allocated equitably to schools that are most in need. There are two broad approaches to recognise different needs across schools when allocating resources: i) including additional resources in the regular allocation (e.g. a weighted allocation to particular student groups within schools using a funding formula); or ii) through targeted programmes or grants for specific students, schools or areas (e.g. extra funding to compensate for socio-economic disadvantage).

Often a mix of both approaches is found in school systems, and many countries provide targeted additional resources "in-kind", typically in the form of teaching hours or positions. For instance, on average across OECD countries and economies, smaller classes are more commonly found in socio-economically disadvantaged or rural schools rather than in advantaged or urban ones. Disadvantaged and rural schools also have, on average, more teachers per students (OECD, 2020[4] ).

The OECD School Resources Review provides some examples for school systems that combine both approaches - including additional resources in the regular allocation and targeted programmes or grants to compensate schools for additional needs:

- In Austria, federal and provincial education authorities (organised jointly within Boards of Education) allocate staff resources to schools according to basic allocation principles, such as the number of pupils and pupils with special education needs. Supplementary staff resources are allocated for the purpose of supporting additional needs related to language tuition needs, socio-economic background, and all-day schooling.

- In Chile, the Preferential School Subsidy (Subvención Escolar Preferencial, SEP) is the main funding allocation (Subvención de Escolaridad) from the central government to school providers for the improvement of schools' quality education. This subsidy is a resource that is granted to the school provider based on the number of priority and preferred students (Alumnos Prioritarios $y$ Preferentes) of the school, their educational level and their attendance at classes. The priority and preferred students are determined based on their socio-economic background or other complementary criteria (e.g. health-related, parental education level, geographic location). The grant represents an acknowledgment that providing quality education in disadvantaged contexts and according to the needs of students and schools has a higher cost, and therefore requires additional resources. The school provider must sign an agreement, knowns as the Equality of Opportunities and Educational Excellence Agreement (Convenio de Igualdad de Oportunidades y Excelencia Educativa), with the education ministry for the corresponding school and commit the use of the resources of this grant to actions, plans or strategies defined in an Educational Improvement Plan (Plan de Mejoramiento Educativo, PME) with special emphasis on priority and preferred students.

- In England (United Kingdom), the central government funds public (local authority maintained schools) and government-dependent private schools (academies) through its Education and Skills Funding Agency (ESFA). While maintained schools receive their funding for current expenditure via their local authorities (Dedicated Schools Grant), academies receive funds directly from the central government. Local authorities also receive Dedicated Schools Grant for students with high needs ("high needs block"). Each local authority is responsible for allocating budgets to their individual schools following a formula that must include a deprivation factor; these local formulas are also used by central government to determine the budgets for the academies situated in each local authority's area. In addition, schools serving disadvantaged students will receive further resources through a targeted programmed (Pupil Premium) which they are free to spend according to their needs but for which they are also held accountable. 
- In New Zealand, schools (which are administered by boards of trustees composed primarily of parents) are funded directly through the central government. While the payroll is covered by the Ministry of Education, each school receives operational funding based on a number of factors which include the socio-economic status of the community and schools' location (adjustments for isolated schools). In addition, the ministry may provide targeted services and programmes. For example, the ministry funds a dedicated learning and behaviour service (Resource Teachers: Learning and Behaviour, RTLB), which is allocated across schools based on student enrolment and socio-economic background.

- In Portugal, teacher resources and funding for current expenditures are mainly distributed across public schools by the Ministry of Education's Institute for Financial Management of Education (Instituto de Gestão Financeira da Educação, IGeFE). For teacher resources, IGeFE allocates to schools the necessary financial resources after school clusters apply for their additional needs to the national administration. For the funding of school expenditure, IGeFE decides on the allocation following a request from the school cluster's board and taking into account a common framework (number of students, number of students with special needs, educational stages and programmes, building structures, historical trends and social context). Additional support is provided to schools through targeted programmes, such as the National Plan of School Achievement (Plano Nacional de Sucesso Escolar, PNSE) and the Education Territories for Priority Intervention programme (Programa Territórios Educativos de Intervenção Prioritária, TEIP). TEIP schools, representing about $16 \%$ of public education, develop their own strategies to address particular needs and submit proposals to central authorities that decide on the suitability for additional funding.

During the COVID-19 pandemic, OECD countries and economies have relied on a range of targeted programmes to bridge equity gaps, through monetary or in-kind resource allocations. Across OECD countries and economies, introducing subsidies for devices (personal computers, laptops) was the most common measure to target populations at risk of exclusion from distance education platforms (OECD, $2021_{[8]}$ ). Countries have also supported programmes to minimise declines in learning achievement due to remote learning periods. Finland, for instance, has funded programmes aimed at limiting learning losses for students with different needs (e.g. students with an immigrant background, students with special education needs) (OECD, 2021 $[8]$ ). In Portugal, all public schools can currently apply for additional resources under the umbrella of the "Plano 21|23 - Escola+", a special programme with more than 40 measures meant to facilitate educational recovery. The programme enables recipient school clusters to hire additional resources (teachers and/or non-teaching staff).

While targeted programmes allow for better steering and monitoring of the use of resources for equity purposes, they can also result in overlaps and inefficiencies and create a lack of predictability about future resource allocations. There are, therefore, arguments to reduce transaction costs by limiting the number of targeted programmes and including adjustments for equity within the main funding allocation.

$$
\begin{aligned}
& \text { More efficiently supporting equity within a } \\
& \text { school system requires striking a balance } \\
& \text { between targeted and regular funding }
\end{aligned}
$$

Also, additional resources for schools may not be sufficient to close gaps in achievement between advantaged and disadvantaged students. Notably, the distribution of staff (which account for the largest part of expenditures and have a significant impact on student learning) needs to be considered. While additional funding can be used to hire more staff, the distribution of staff is also influenced by other factors, such as recruitment processes and staff preferences and incentives (see (OECD, 2019 ${ }_{[11]}$ ). 


\section{The role of funding formulas}

A well-designed funding formula can promote equity and efficiency. A funding formula is a set of agreed criteria which are applied to each individual school, normally through a mathematical formula making the coefficients attached to each criterion explicit. Formula-based funding can help establish a clear framework for debates on the sufficiency and equity of resource allocations and, in some systems, funding formulas have helped build general acceptance of resource allocations as fair among stakeholders. Funding formulas are used in many countries to distribute regular funding for current expenditures such as staff salaries. Austria, Chile, England (United Kingdom) and New Zealand in the examples above all use formulas to distribute resources through the main allocation and targeted funds.

One major challenge in designing funding formulas is to adequately reflect that it does not cost the same to educate all students. There will be a need to fund schools differentially for legitimate differences in unit costs which are beyond the control of the school. This demands the introduction of different adjustment components in the formula and could lead to a high degree of complexity. A balance needs to be struck between a simple formula, which might fail to capture school needs with full accuracy, and a sophisticated formula, which might be difficult to understand.

As a guide for designing formulas to better meet differing needs, research has identified four main components: i) a basic allocation; ii) an allocation for a specific educational provision; iii) an allocation for students with supplementary needs; and iv) an allocation for specific needs related to school site/location. Comprehensive and compelling analysis, and empirical evidence on the exact cost differences can strengthen the basis for policy decisions to review or adjust parameters included in funding mechanisms. Reliable evidence should be gathered on the adequacy of funding in general, and on specific elements that funding mechanisms aim to address, e.g. equity problems related to socio-economic disadvantages, concerns for a more equitable distribution of funding in rural locations and the education of students with special educational needs.

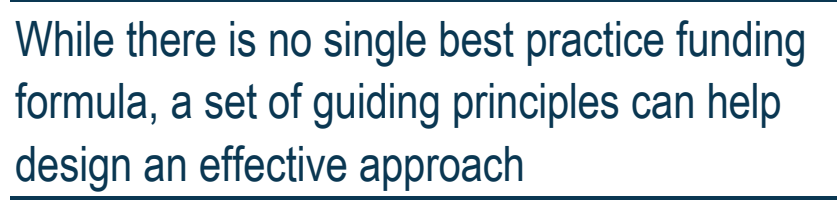

Systems also need to pay adequate attention to the choice of indicators and the availability and quality of the related data when designing a funding allocation mechanism. A wide range of indicators are used across countries to distribute funding to schools. For instance, area-based funding aims to address the additional negative effects that socio-economic disadvantage has when it is concentrated in a particular area. However, such approaches risk leaving out a proportion of the disadvantaged population and include many individuals who are not disadvantaged. There is also evidence that the "target area" label can be stigmatising and encourage flight of middle class families from these areas. As a result, there has been a broad shift to using indicators that are more specific to the actual population in the school.

In all cases, whether indicators target specific areas, schools or students, there is a trade-off between simplicity and transparency, on the one hand, and accuracy and fairness, on the other. Relatively simple indicators are likely to leave out some parts of the target population but also disregard certain sources of higher cost more broadly (e.g. school size). For more precise targeting, more complex indicators need to be established, although a higher degree of complexity makes these less transparent and understandable to administrators, schools and the wider public. In many countries there is an ongoing debate as to how many indicators should be included, and there are examples where the use of simpler indicators did not make a large difference to schools' funding levels.

Many school funding systems aim to strike a balance between using census-based and school-based indicators. While the use of census-based data has been criticised in some systems for being out of date, 
such data cannot be manipulated by schools when there is incentive to inflate or deflate numbers in order to benefit from additional resources, thus giving greater integrity to the funding system. A further problem is the misclassification and missing data on part of schools or students. Using census-based data as a proxy for individual student needs can be less accurate in targeting individual students, but national research can help choose the best proxy indicator or combination of indicators. This also holds the advantage of reducing the reporting burden on schools.

All systems should make sure to regularly
review the indicators used to allocate
resources to ensure that they reflect evolutions
in data systems

The following country examples illustrate some OECD countries' approaches to funding formulas:

- In the French Community of Belgium, for example, school leaders report every year the school population (of January) to the central level which attributes a socio-economic index value to every pupil according to their residential area. The index of the residential area is based on individual characteristics such as income, qualification level and unemployment rate (and is reviewed every five years). Schools are then ranked according to their average socio-economic index value, and $25 \%$ of schools with the lowest values qualify for additional teaching periods or funding allocations (at primary and secondary levels).

- In the Netherlands, the central government provides schools for primary and secondary education with a lump-sum funding. The Netherlands relies on formula-based funding using objective criteria with a universally applied rule to determine the amount of resources each school is entitled to, for personnel and material financing. The main criteria for funding allocation are the number of students at October 1st of the preceding year, the type of school, the size of the school and, in primary education, the age of teachers. As part of the lump-sum, schools receive extra funding for students with a risk of educational disadvantage. Educational disadvantage is measured based on several variables, such as parental educational attainment, origin of the mother or whether parents are in debt restructuring. Thus, the funding has a micro- as well as a macro-level component.

\section{Box 1. How to provide resources for students with special educational needs?}

Needs-based allocation mechanisms to provide additional resources for students with special educational needs (SEN) are intuitive and can be perceived as fair. In Chile, the education ministry provides funding to school providers for the inclusion of SEN students in school system via its School Integration Programme (Programa de Integración Escolar, PIE). By law, schools can receive a grant for up to seven SEN students per class (five students with transitory disabilities and two with permanent disabilities). The resources of this programme are provided to be used in the purchase of specialised and/or adapted educational materials, hiring specialist staff, for training and coordination, and for collaborative work and planning.

Needs-based allocation mechanisms may however have some undesirable effects. When funding is directly linked to the identification of individual students as having special 
educational needs, this may lead to excessive labelling of students which is stigmatising for individuals and can lead to considerable cost inflation. To avoid inflation of the numbers of students identified over time and inconsistent categorisations, the criteria used for assessing students as having physical or learning impairments should be transparent, unambiguous and applied impartially by educational psychologists (also see (OECD, 2018[12])).

Several countries use individually targeted funding for students with more severe special educational needs, complemented by census-based funding for students with milder special educational needs or those linked to socio-economic disadvantage. Examples of such indicators are variables measuring social disadvantage (such as poverty, unemployment, poor housing, and low education level) in the immediate community of the school. Such indicators hold the advantage that schools cannot manipulate them. Another way of reducing the incentive for excessive labelling of individual students is to allocate some of the funding for students with SEN to all schools, as a fixed percentage of their formula budget.

Some systems may not use any funding earmarked for special needs students and this may risk the perception that funding is not allocated to support the learning of students with SEN. In such a context, stronger accountability at the school level with scrutiny by school boards on the educational provision in the school for students with SEN and the impact it is having on their learning will play a key role.

The OECD School Resources Review of Denmark (Nusche et al., 2016 ${ }_{[13]}$ ), for example, found that municipalities rely to a decreasing extent on earmarked funding to individual students with SEN and more on general funding. In the more general approach, resources for students with SEN are allocated across schools with respect to general criteria measuring the socio-economic background of students. This approach aims to give schools the flexibility to optimally use these resources, taking factors such as the characteristics of peers into account when allocating resources. However, it has also raised some concerns over a lack of transparency on how resources follow students into regular schools and whether they receive adequate learning support. The OECD review therefore recommended greater transparency to the school community about how the school uses resources to facilitate inclusion and the way this translates into learning outcomes for SEN students.

\section{Political economy of reform and implementation costs}

There will always be winners and losers when changing an existing funding model unless additional resources are made available. Experiences in many countries thus highlight the importance of effectively managing the political economy of funding reform and of having a realistic estimate of its implementation costs. Adequate stakeholder consultation is important to increase the perceived fairness of an allocation system and can help ensure that funding mechanisms respond to challenges that were not anticipated.

In Austria, for example, the introduction of socio-economic criteria into the existing formula to distribute resources was a topic of much debate. While social partners supported the introduction of an index-based resource distribution, some provinces with a large share of rural schools were opposed to this change since it would likely result in the redistribution of funding from rural to urban schools. As part of a major school reform in 2017, the education ministry was given the possibility to set socio-economic index into the resource allocation, but this required the introduction of regulations. In England and New Zealand, changes to the existing funding allocation model over the recent years have been controversial as well.

Example for the costs of implementation come from Australia and the Flemish Community of Belgium. In Australia, the government explicitly made the promise that no school would lose funding when responding 
to a major review of the country's funding model. The aim of the review was to better ensure adequate funding for students with greater educational needs. As such, the government needed to commit significant additional resources to implement the funding reform. In the Flemish Community, changes to the system for distributing operating grants and staffing went in line with substantial increases in the overall budget.

\section{Promoting transparency and monitoring equity outcomes}

Many school systems invest considerable resources to improve the educational opportunities and outcomes for student groups at risk of underperformance. But this financial commitment is not always matched with a strategy for monitoring the progress and outcomes of these groups. Monitoring equity can inform school funding decisions to the benefit of disadvantaged groups, help to target financial support more effectively, and increase the overall focus on equity in resource use decisions across the system.

Countries should set clear equity goals for the system and develop related indicators to monitor their achievement. This should entail the collection and analysis of data on the demographic characteristics of schools and students and the learning and other outcomes of disadvantaged students, for example through national assessments and labour force surveys. Key data on learning outcomes should be sufficiently broken down for different student groups to facilitate analysis of the challenges they face. Disaggregated data can also help to facilitate peer learning among schools with a similar student intake and similar challenges. Commissioning thematic studies on the use of resources for equity is another option for monitoring the equity of the school system. Where multiple equity programmes are in place serving similar goals, it is important to approach evaluation from a whole-of-government perspective.

In systems with considerable resource autonomy for schools, school leaders also need to make equity judgements when allocating resources between different age groups, curriculum areas, courses, and students with different learning needs. In such contexts, it is also important to monitor how schools use their funding to provide high quality teaching and learning for all of their students. School boards can play an important role in discussing the use of funding for different student groups with the school leadership.

Promoting budgetary transparency needs to be another key goal for school systems. Budgetary reporting linking evidence about the quality and equity of the school system in relation to established policy objectives and targets can provide clear information for decision-making and strengthen public participation, discussion and oversight. Differences in expenditure levels between regions/states/localities and schools can stem from a number of issues, such as different levels of efficiency or political decisions. Any inequities in available resources between schools and providers that may be linked to funding and governance arrangements should however be made transparent. In countries where public schools are allowed to raise their own financial resources in addition to public funding (e.g. by providing extracurricular activities or renting out facilities), for example, these resources should be accounted for in their budgets.

Transparency is particularly important in complex governance systems where resources intended for disadvantaged groups are channelled through several tiers of administration. Local or school autonomy in spending decisions may mean that central equity funding strategies may be undermined at the local or school level if equity funding is shifted towards other student groups or allocated to purposes that have little effect on target groups. The distribution and use of funding and the actual expenditure outputs (the real cost of educating a student as opposed to the planned funding per student) within schools should be transparent.

Box 2. Tracking school-level expenditure data in the United States

Concerns about the equitable distribution of school funding within and across school districts in the United States have led to new federal data collections on school-level expenditures. 
Many school districts in the United States do not have experience in systematically tracking expenditures at the school level, and the quality of these large-scale data collections is uncertain. To better understand the feasibility of broadening the collection and reporting of detailed school-level expenditure data, and improving the quality of such data, a mixed method study by the United States Department of Education examined five states and four school districts that have developed their own accounting systems for school-level expenditures. While findings are not generalisable, they may be useful to inform efforts to implement school-level expenditure reporting systems, particularly in large urban areas that were the subject of this study.

The states and districts that participated in the study had been collecting and reporting school-level expenditure data for varying amounts of time and reported similar motivations for developing or expanding their school expenditure data systems. Reasons include a response to the introduction of state laws intended to promote equity and transparency in school spending and district efforts to give schools more authority over spending decisions. To implement a system for collecting school-level expenditure data, authorities typically had to invest in new hardware and software, make changes to charts of accounts, and train their staff. They incurred both personnel and non-personnel expenses, which included staff time spent to choose and/or design the data system, to plan system roll out strategies and to develop training materials, as well as contracts with vendors or consultants and technology upgrades. Commonly identified challenges in developing a system to track school-level expenditure data included staff capacity and training.

As the study demonstrates, collecting and reporting high quality school-level expenditure data is feasible and has perceived benefits for transparency, equity, and the efficient use of resources. A key challenge in the process of collecting and reporting school-level expenditure data lies in ensuring consistency in practices surrounding the attribution of funds to schools both within and across districts and states.

Source: US Department of Education, Office of Planning, Evaluation and Policy Development, Policy and Program Studies Service (2017 [14]), Exploring the Quality of School-Level Expenditure Data: Practices and Lessons Learned in Nine Sites, https://www2.ed.gov/about/offices/list/opepd/ppss/reports.html (accessed on 14 October 2021).

\section{The bottom line:}

Efficiency alone is not the main concern of school systems but needs to be achieved alongside the quality and equity objectives that are at the heart of schooling. School funding policies should be designed so that available resources are directed to supporting high quality teaching and providing equitable learning opportunities for all students. School systems need to match resources with learner needs, striking a balance between targeted and regular funding. Funding formulas are particularly well suited to provide the resources required in vulnerable contexts and to foster debate about the distribution of resources. Investments in the educational opportunities for vulnerable students should be matched with a strategy for monitoring the progress and outcomes of these groups. 


\section{School Resources}

This document was prepared by the School Resources team at the OECD. It

is based on thematic reports and country-specific work, with analytical contributions from: Luka Boeskens, David Liebowitz, Andreea Minea-Pic, Deborah Nusche, Thomas Radinger, Paulo Santiago and Claire Shewbridge.

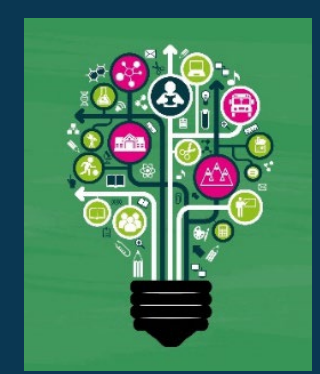

\section{For more information}

Contact: Karine Tremblay, project leader, Karine.Tremblay@oecd.org

See: OECD School Resources Review

OECD (2017), The Funding of School Education: Connecting Resources and Learning, OECD Reviews of School Resources, OECD Publishing, Paris

\section{References}

Jackson, C. (2018), "Does School Spending Matter? The New Literature on an Old Question”, NBER

Working Paper, No. 25368, National Bureau of Economic Research, Cambridge, MA.

Jackson, C., R. Johnson and C. Persico (2016), "The Effects of School Spending on Educational and

Economic Outcomes: Evidence from School Finance Reforms", The Quarterly Journal of Economics, Vol. 131/1, pp. 157-218, http://dx.doi.org/10.1093/qje/qjv036.

Johnson, R. and C. Jackson (2019), "Reducing Inequality through Dynamic Complementarity: Evidence from Head Start and Public School Spending", American Economic Journal: Economic Policy, Vol. 11/4, pp. 310-349, http://dx.doi.org/10.1257/pol.20180510.

Lafortune, J., J. Rothstein and D. Schanzenbach (2018), "School Finance Reform and the Distribution of Student Achievement”, American Economic Journal: Applied Economics, Vol. 10/2, pp. 1-26, http://dx.doi.org/10.1257/app.20160567.

Nusche, D. et al. (2016), OECD Reviews of School Resources: Denmark 2016, OECD Publishing, Paris.

OECD (2021), Education in Brazil: An International Perspective, OECD Publishing, Paris, https://www.oecdilibrary.org/docserver/60a667f7en.pdf?expires $=1632831848 \&$ id $=i d \& a c c n a m e=0$ cid84004878\&checksum=EB874598443BCC860616D8 B0F724B8F0 (accessed on 28 September 2021).

OECD (2021), Education at a Glance 2021: OECD Indicators, OECD Publishing, Paris, https://dx.doi.org/10.1787/b35a14e5-en.

OECD (2021), OECD Economic Outlook, Interim Report September 2021: Keeping the Recovery on Track, OECD Publishing, Paris, https://dx.doi.org/10.1787/490d4832-en.

OECD (2021), The State of Global Education: 18 Months into the Pandemic, OECD Publishing, Paris, https://www.oecd-ilibrary.org/docserver/1a23bb23- 
en.pdf?expires $=1632472645 \&$ id $=i d \&$ accname=ocid84004878\&checksum=4A783BF4B0A2B00DD71BC 5777C218D7D (accessed on 24 September 2021).

OECD (2021), The State of School Education: One Year into the COVID Pandemic, OECD Publishing,

Paris, https://www.oecd-ilibrary.org/docserver/201dde84en.pdf?expires=1632997342\&id=id\&accname=guest\&checksum=AB7A563077A4309BB5207DC1BF8D $\underline{8508}$ (accessed on 30 September 2021).

OECD (2020), PISA 2018 Results (Volume V): Effective Policies, Successful Schools, PISA, OECD

Publishing, Paris, https://doi.org/10.1787/ca768d40-en (accessed on 1 February 2021).

OECD (2019), Working and Learning Together: Rethinking Human Resource Policies for Schools, OECD

Reviews of School Resources, OECD Publishing, Paris, https://dx.doi.org/10.1787/b7aaf050-en.

OECD (2018), Responsive School Systems: Connecting Facilities, Sectors and Programmes for Student Success, OECD Reviews of School Resources, OECD Publishing, Paris, https://dx.doi.org/10.1787/9789264306707-en.

US Department of Education, Office of Planning, Evaluation and Policy Development, Policy and Program Studies Service (2017), "Exploring the Quality of School-Level Expenditure Data: Practices and Lessons Learned in Nine Sites", https://www2.ed.gov/about/offices/list/opepd/ppss/reports.html.

This work is published under the responsibility of the Secretary-General of the OECD. The opinions expressed and arguments employed herein do not necessarily reflect the official views of OECD member countries.

This document, as well as any data and any map included herein, are without prejudice to the status of or sovereignty over any territory, to the delimitation of international frontiers and boundaries and to the name of any territory, city or area.

The statistical data for Israel are supplied by and are under the responsibility of the relevant Israeli authorities. The use of such data by the OECD is without prejudice to the status of the Golan Heights, East Jerusalem and Israeli settlements in the West Bank under the terms of international law.

You can copy, download or print OECD content for your own use, and you can include excerpts from OECD publications, databases and multimedia products in your own documents, presentations, blogs, websites and teaching materials, provided that suitable acknowledgment of OECD as source and copyright owner is given. All requests for commercial use and translation rights should be submitted to rights@oecd.org. 